Recibido: 05--09-2016

Aceptado: 23-09-2016

Palabras clave: Violencia sexual. Keywords: Sexual violence.

Gloria Acosta de Hoyle gloriaacostaa@unife.edu.pe UNJFE

\section{Mi propia experiencia de violación sexual: Una mirada al proceso realizar una denuncia por Violación sexual para una mujer en Lima}

My own experience of rape

\author{
Gloria María Acosta Álvarez de Hoyle
}

PREFACIO Sin duda atraídos por el titulo de la investigación podemos basarnos en una sórdida lectura de algún caso conc(eto - y basta cercano- de violencia sexual y es que más allá de los casos expuestos en los que podríamos asumir que una violación sexual es .lo peor que podáa pasarle a la víctima;la lectura de hoy lo trasladará al mundo de la denuncia por violación.

Mj experiencia profesional, sin duda en el ámbito corporativo, me llevó a una negación de la realidad, pensando orno muchos- que al no ser un especialista en género, ni ser penalista, no podía hacer nada al respecto. En este espacio de tranquilidad tuve que afrontar una situación pecuLiar. .. una persona muy cercana a mi, me llamó de madrugada un dfa para pedirme un auxilio entre Uanto, y aún diciéndome gue por favor no lo comente a nadie de nuestros amigos cercanos, ni familiares, pues aún se encontraba mareada y clue no entendía que había ocurrido. Por el nivel de confianza que nos teníamos, reconocí la gravedad del tema ... muchas veces viajeras solas, otras acompañadas, ella esta vez había realizado un viaje por trabajo al mterior del país, en el cual se había encontrado con unos compañeros "amigos" quienes la invittllon a una reunión en la que lamentablemente fue drogada y violada.

Es inlinitamente menor el dolor que puedo transmitir en estas líneas, pero ante el desconocimiento de la simación opté por decirle gue denuncie inmediatamen te eo la comisaria más cercana; sin embargo había una crisis adicional que atender... el sentirse culpable de lo que había ocurrido, el hecho de haber viajado por un espacio de trabajo y asistir sola a una reunión social, el no poder comentarle a nadie de su entorno cercano y tener que validar el no poder asistir a su centro de labores aquella mañana. Temas que sobrellevamos en el momento.

Opté por apoyarme en un amigo cercano, abogado especialista en la materia, quien me sugi1ió su pronto retorno a Lima y que desde la comisaría de su distrito realizáramos la denuncia... agradecida por todo su apo\}'O, logré convencer a la dccima en abordar un tax.i; que la condujo por dos horas hacia el aeropuerto más cercano, para que luego de un sinfín de peipecias, lograr hacerla abordar al avión; no sin antes precisarle gue no tome nada, ni agua, ni se bañe, solo gue coloque la ropa con Ja cual había amanecido en una bolsa apárte y que se traslade inmediatamente. Más allá de todo lo traumático de vil'ir una e.."Xperiencia cercana como la descrita tuve que vivir en carne propia una experiencia, a mi crirerio, hasta ahora inverosímil: el realizar la denw1cia. Encontrándose en Lima, .la acompañé a asentar la denuncia en compañia de mi esposo; de mi amigo penalista y de dos policías en ejercicio, con lo que sinceramente pensé que el rema podáa Auir rápidamente. Cuál no seáa mi sorpres-a al encontrarme con un escenario mtalmeote diferente al que hubiera imaginado. 


\section{INTRODUCCIÓN}

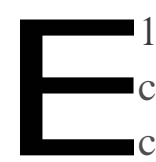

trámite de denuncia por violencia sexual cuya víctima es una mujer en la ciudad capital denota un alto grado de complejidad que no es percibida por el comt1n de las personas. Se trata entonces de información no difundida, por lo tanto poco conocida $y$ sobre todo en la práctica, generando un desincen tivo mayor para la victima y por gué no decirlo un maltrato tangfüle hacia quien se anima a realizar la denuncia.

Muchas veces hemos escuchado... "pero sj se trata de casos aislados, si tan afectada está, entonces ¿Por qué una mujer no denuncia?". Lo cierto es que desde una perspectiva psicológica, la afectación de la victima es tal que los criterios por los que no se produce una denuncia resulta de diversa índole.

Pese a ello, para quienes han tenido la "suerte" de no ser víctimas de feminicidio , quienes han sobrevivido a la violencia sexual y tienen la valenúa de denunciarlo, la historia recién 11liCla.

Respecto del trámite de la denuncia materia de la presente investigación, he podido constatar que los casos de atención directa en comisarías, juzgados de paz y sobre todo Línea 100 del Ministerio de la mujer y poblaciones vulnerables, no culminan en ese estadio. Esto es, la víctima debe necesariamente trasladarse por lo menos en dos sedes diferentes para realizar la evaluación de médico legista y pericia psicológica.

El estudio presenta uo aspecto nuevo, dado c1ue no hemos ubicado investigación similar para proporcionar un conocimiento relevante en el tema de investigación proporcionando una propuesta de política pública; en este sentido el estado de la cuestión responde al tema estudiado y en políticas para erradicar la violencia hacia la mujer.

Resulta claro que al contar con el $80^{10} \%$ de denuncias por violación sexual realizadas por los familiares directos de los niños y niñas víctimas por violación sexual según la fiscalía de la nación
, resulta lógico priorizar la atención estatal en este tipo de denuncias; aplicamos una Ley de Pareto para que contando con w1porcentaje mayoritario al cual se debe atender como prioridad - basta de asignación de presupuesto - para estos casos, pero nos olvidamos de todas aquellas denuncias que no se realizan. Pues claro, gujen soporta la denuncia en caso de menor son los familiares directos; pero en el caso de una víctima mujer debe sopesar un sin número de factores para hacer realidad dicha denuncia, por lo cual nos encontramos con cifras ocultas en elanál isis que resultan difíciles de tomar en cuenta para considerar efectividad en la toma de decisiones, más aún considerando la división de presupuestal a nivel del Ministerio, por contar con poblaciones vulnerables con requerimientos inmediatos urgentes.

Reconozco gue el M.inisterio de la Mujer y Poblaciones vulnerables realiza el mayor esfuerzo y que la política de Estado se encuentra en línea con las normas vigen tes; sin embargo el análisis materia del presente estudio se refiere únicamente al estadío de la denuncia, para poder proponer medidas concretas; no respecto de todos los problemas de la violencia de género.

Los resultados responden a los objetivos propuestos de mejorar el proceso de denuncias ante casos de violencia sexual contra las mujeres. En este sentido, Ja innovación propuesta no sólo está relacionada con la creación de nuevos sistemas ni tecnologías avanzadas, ya gue aprovecharemos actividades existentes para poder optimizar el proceso y lograr un resultado eficiente, dentro de lo duro que puede ser tratar con las víctimas por violación sexual.

En estesentido,brindamos recomendaciones concretas en políticas públicas clue espero de alguna manera pudieran ser implementadas a fin de conseguir los mejores resultados posibles. En las que estoy convencida que las acciones que tomamos como particulares en la academia, sociedad civil y en particular el Estado pueden ayudarnos a que suimpacto sea más transformador. 
1. Planteamiento, Marco teórico-conceptual y formulación

\section{a. Planteamiento del Problema}

En la ciudad capital, existen un proceso estandarizado para realizar una denuncia penal por violación se\}.'.Ual contando con lavictima una mujer, sobre el particular la víctima debe encontrarse con diversos estadios de revisión como se detalla:

I. Información dispersa de la forma como realizar la denuncia )r trámites a seguir.
2. Realizar la denuncia en la comisada de su distrito o donde haya ocurrido el hecho

3. Someterse a la revisión/ inspección física de un médico legista

4. Someterse a pruebas adicionales: Orina, sangre, restos en las uñas, esputo, entre otras.

S. Someterse a peritaje psicológico

En cada uno de estos espacios, la víctima vuelve a revivir su drama y volver a contar la historia a las personas que le atienden ocasionando revictimización innecesaria.

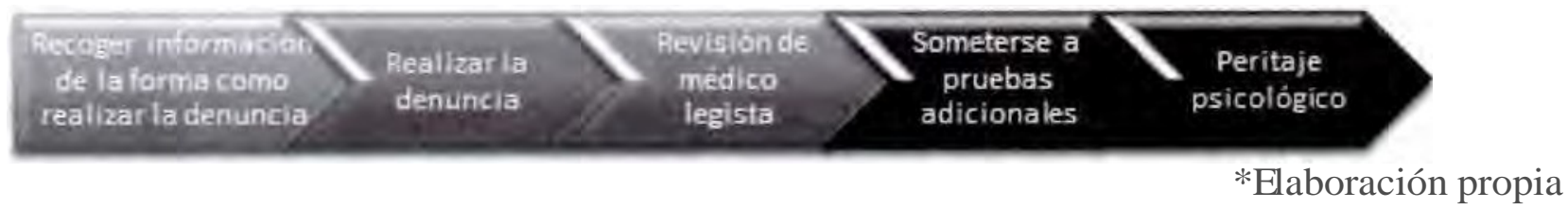

La pnmera etapa de recolección de a un proceso de prevenc1on sensibilización y información se tiene en cuenta al considerar conocimiento general de la situación.

que la víctima recién recibe dicha información al momento que decide realizar la denuncia. Tiempo valioso sobre el que resulta necesario reflexionar pues como veremos más adelante correspondería

La única información contenida en la Web institucional del Nlinisterio de la Mujer y poblaciones vulnerables es la que se detalla en la Imagen como Paso 1 y Paso 2.

\section{Paso 1: ¿Quién puede denunciar?}

Lavktima o cualquier persona que conozca de la violencia. La denuncia puede ser presentada en forma verbal o escrita. Es importante que lleve su documento de identidad (DNQ.

Defensores de las DEMUNASy Directores de colegiostienenlaobligación de poner en conocimiento alas autoridades policiales y judiciales los casos de violencia sexual en agravio de niñas, niños y adolescentes de los que tengan conocimiento.

Llameal 105, en caso de producirseactos de violencia gaves en el momento . (Centraltelefónica dela Policía Nacional del Perú). 


\section{Paso 2: ¿Dónde se denuncia?}

\section{En la Policía Nacional:}

A través de cualquier comisaría, de preferencia del sec1or en el que vive o donde han ocurrido los hechos. La comisa ría recibe las denuncias por violencia familiar y realiza las investigaciones preliminares y las notificaciones correspondientes. Está facultada para allanar el domicilio del agresor en caso de flagrante delito o de muy grave peligro.

\section{En el Ministerio P(1blico:}

Ante el Fiscal Provincial de Família o Mixto que corresponda. Tramita las peticiones escritas o verbales o por emisión del atestado policial. También puede actuar de oficio ante elconocimiento de los hechos

\section{En el Poder Judicial:}

El Juez de Fanlia Mixt o o de Paz, según sea el caso, es el que recepciona las acciones porviolencia familiar.

"Recuerde que es importante que detalle los hechos en forma ordenada y clara a fin de facilitar la investigación. Proporcione el nombre del agresor si lo conoce, así corno las señas y direcciones que hagan posible su detención.

*Fuente: Miniscerio de la Mujer y Poblaciones vulnerables

A partir de la segunda etapa de realización de la denuncia para rrasla $<$ lo a médico legistn como prueba esencitl es necesario crabajarlo a la brevedad posible, es allí donde se dispone de ser el caso, del ttaslado para análisis de laboratorio adicionales, los cuales no se encuentran en la mísma sede de la elaluación del médico legista, por motivos de costos. En esce sentido se solicita a la víctima trasladarse a la Morgue Central de Lima pues es donde se encuentran los reactivos para poder realizar los análisis.

Cabe anotar que en eJ caso de Ja evaluación de médico legista, la víctima se encuen tra en espera según orden de llegada, no puede ser acompañada por ninguna persona (ni familiar, ni abogado), durante esa espera no solo comparte la fila con otras 'ÍCtimas, sino también con ottas personas que deben realizar un trámite frente a médico legista. A saber, personas detenidas por haber cometido supuestos delitos de difereme gravedad.
Según hemos comprobado, los análisis adicionales son enttegados por la victima en el In sti tuto de Medicina Legaldel Ministerio público, el cual conocemos como la Morgue Central de Lima, donde no ha)' ninguna orden de prioridad asignada y como sabemos la atención es para practicar principalmente necropsias, donde se cuentacon un sinnúmerodecarenciasyexponenala víctima a con traer un sin número de enfermedades

Si bien no se cuen ta con u na guía para el desarrolln de la denuncia para mujeres se utiliza la Guía de Procedimiento para la Entrevista Única de Niños, Niñas y Adolescentes víctimas de abuso sexual, explotación sexual y trata con fines de explotación sema donde se detallan las etapas prevjarnentc anotadas:

./ Etapa Previa: que incluye la denuncia y evaluación médico legal

./ Etapa de Entrevista Ú nica, 


\section{UNIFÉ -EPG}

./ Etapa Posterior: gue incluye la evaluación psicológica y la derivación para su tratamiento a los servicios de salud y a la unidad de víctimas y testigos cuando corresponda.
Es así como en Ja etapa previa señalada por la guía se mantiene un proceso de evaluación física de la Integridad sexual, conforme se detalla a continuación.

\section{PROCESO DE EVALUA CIÓN FíSICA DE LA INTEGRIDAD SEXUAL}
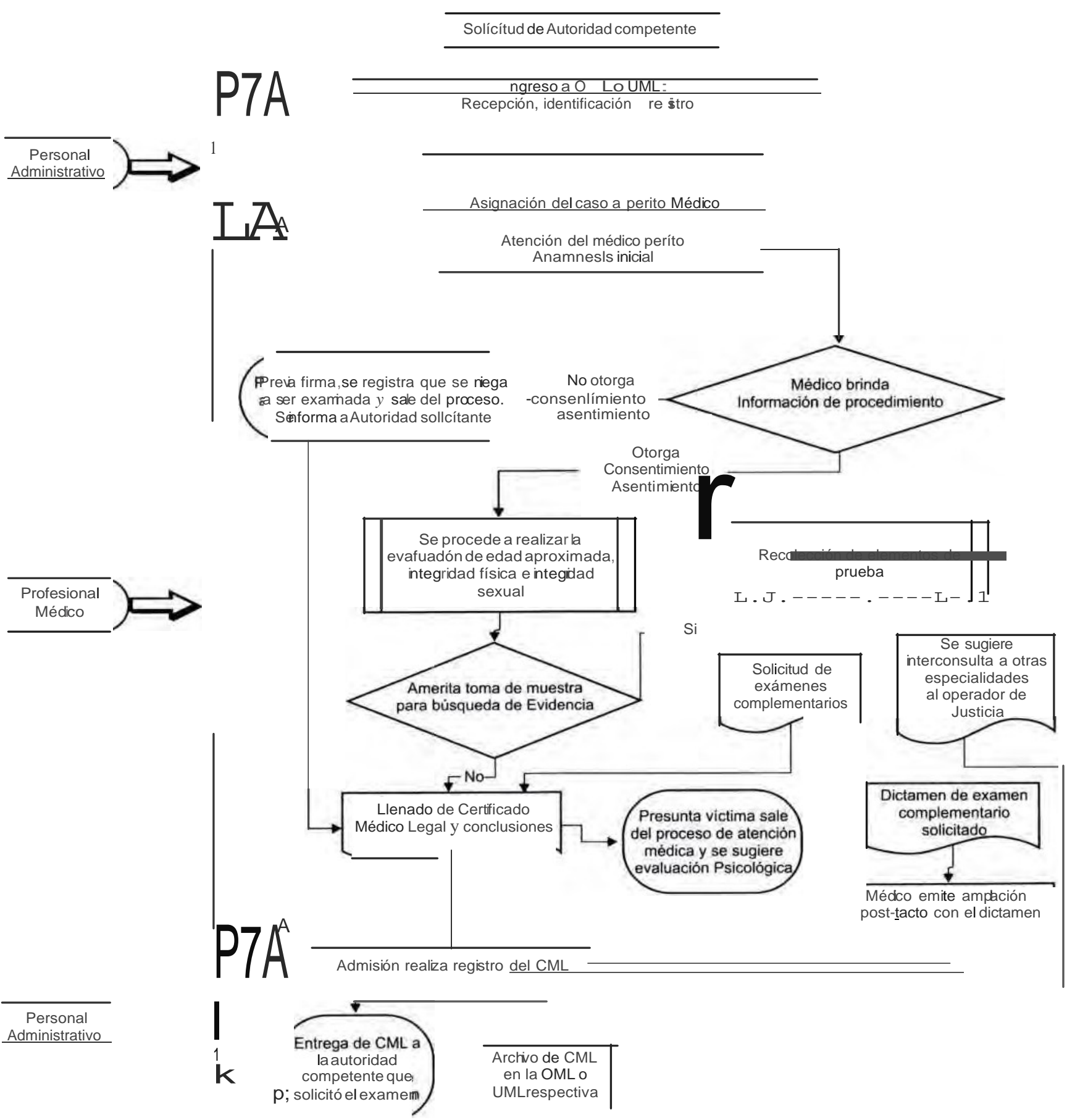

*Fuente: Guía Medicina Legal : Violencia Sexual 
Stguo el Pla n Nac1on:1I de l ldad dep,.énero del Ministerio de la Mujer y poblaciones vulnerable !t el 38,4\% de las mujeres que han vivido alguna viz en unión de p:m:ț, señala haber sufrido viokncrn fisica $\mathrm{y} / \mathrm{o}$ sexual. Adiciormlmcmc nos inclirn que al mes. en prom $<$ :dio. 10 mujeres son victima de feminicidio. Finalmente no hay daros estadísticos oficiales sobre la dimensión dd problemit dthostigamiento sexual, ni violaciones sexuales no denunciadas .

Si bien el Programa Nacional contra la liolencin fruniliar y sexual precisa como logros en d primer semestre del año 2015:28,79() mujeres r1tc:ncüd:1\$ por bcchos de violcnci3 famil iar y sexual en los ervicios de emergencia mujer y 786,672 actividades de arenaón psicológica, legal I' nsisrcncia social. Así como diversas actiddades de sensibilización contm laviolencia. Sin embargo, de esms casos -que reconocemos no son los thicoscn $\mathrm{t}: \mathrm{I}$ mismo periodo se rcdbicron alrcdtdor do:: J,000 denuncias scglin el informe de J NF.I

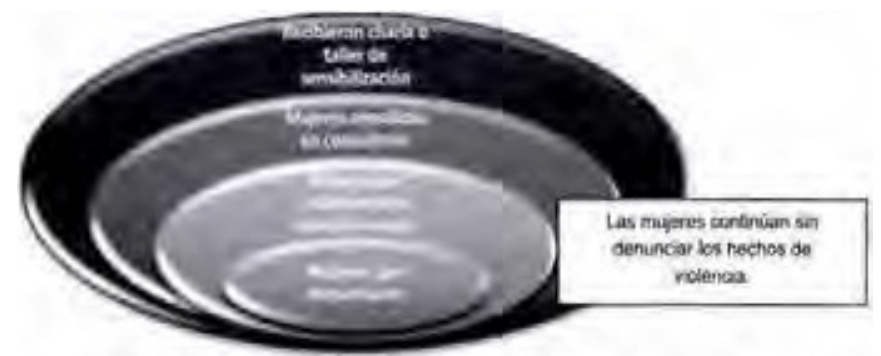

-F'ucnrc: linircrio de $\mathbb{1 1}$ 1ujcr - Pot,Incioncs vulncr:1hlc.

Ebbor:iciña propi:t

Rcspecm de l;i cantidad de denuncias 1elizaJas presen tamos el siguien te cuadm fosumen que nos brinda urı pnnorama general de
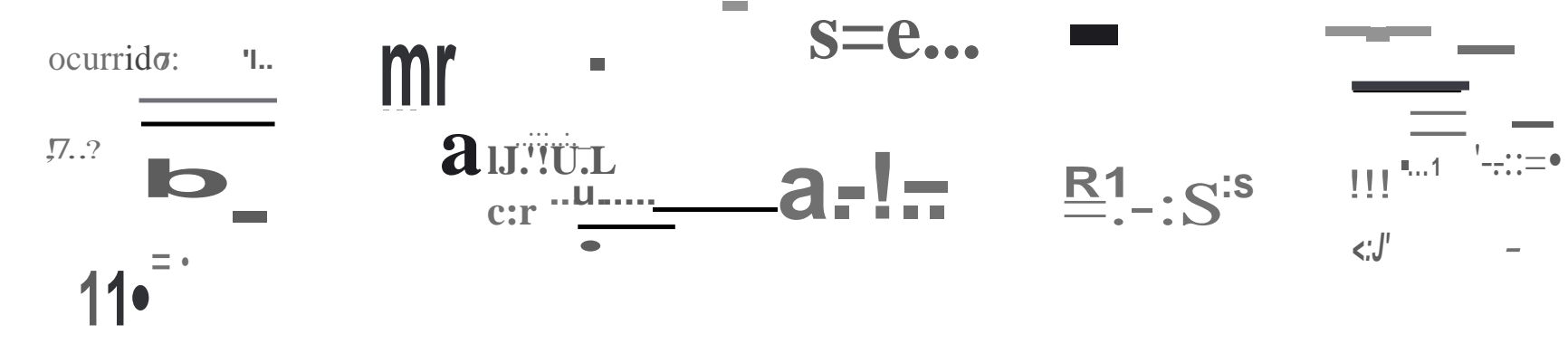
ínvcsúgación ampliada respccco de rodo el proceso a seguir por concepto de violación sexua.1; yn qu reconocemos la e.. fatencia de falencias asociadas ni proceso núsmo, pero sería nbarc $<1$ r un terreno más amphu $r$ lo yuc tnurunos de moscr $r$ es conscgu $1 \mathrm{t}$ accillnes concretas rntc el problcm planreacln.

Nos hemos permitido acorar la invesrigacié> $n$ en el estadio preliminar de prescnración ele In denu ncia, bajo el argumcn ro de mejorar el ingrel;o de- 19s denuncias e incentivar a las vicámas de violación a pn;scntar la denuncia corr $<$ spondieotc. Ello nús convocará a f11nlrns mvestigacione:s en la que esperamos coni.imrn $r$ abordando espacios de políticas públicas en pro de equidad de género. 
ti fill 1A..62.s=-- IC - 48\%;:;::::::>.. 90"::.;.,.TM 925::- ==

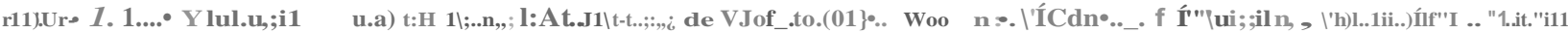
fuu 1.e:: li.ui" U/lt.wr-u2: 1 I"॰/nu.1luun_.J....,/iu-a..t: $\operatorname{sen} / 1$ 1-.2.l•J·t l 
Pese a que en el s1gweore auadro se recoge mior11he1ón al 2012 c•msidcramos 'i!Jd;t la 1!'llluación pa ra r•)nderar la evolución de ln caso< informados:
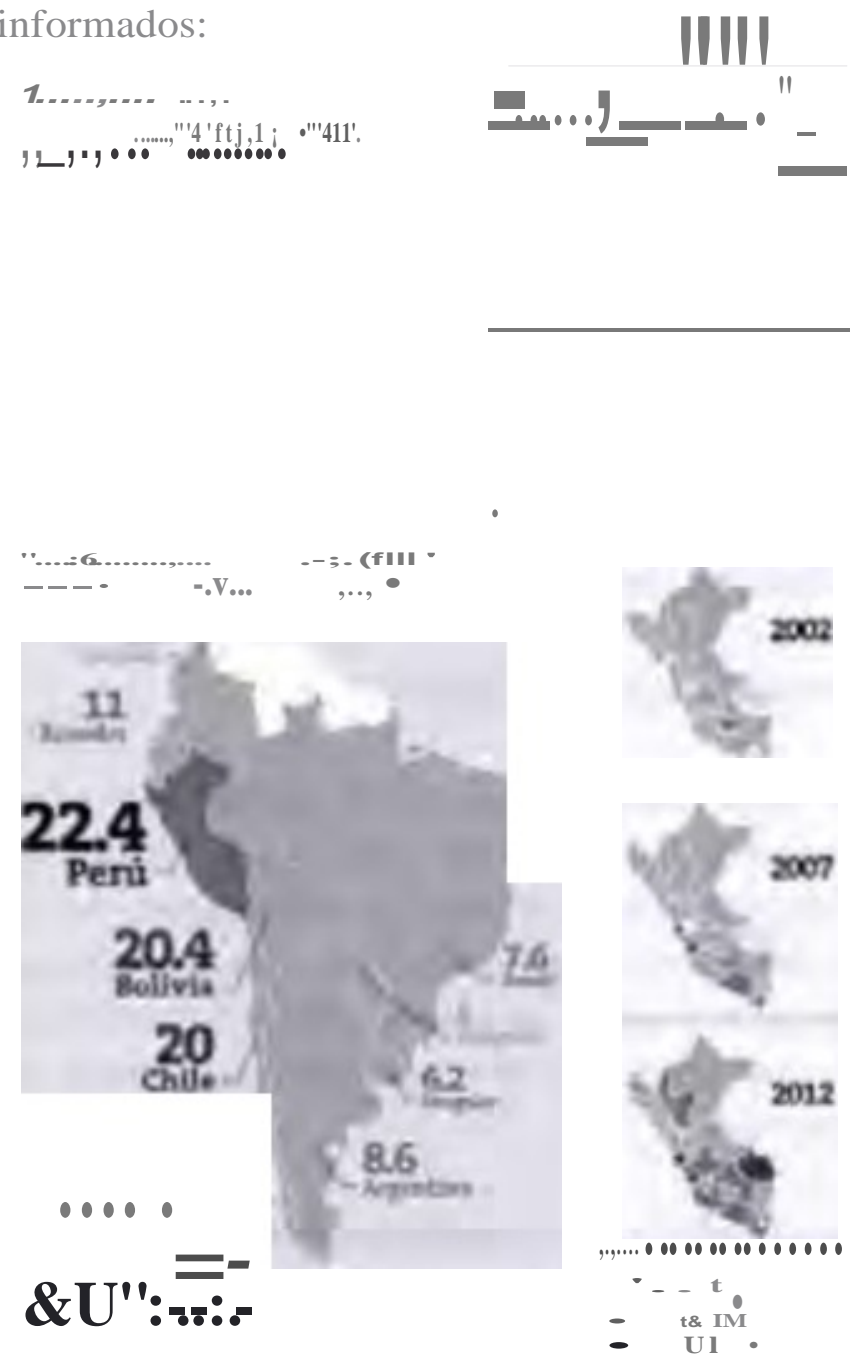

L3 mvcsugac1ón propuesta se 1u>tilica pur la nccc. idad de optimiznr la cfic:ienc1a <lel procc. o de dcnunc1A mujer \'Ícrima de una \•iol:icion <cxual, luego de rel •ar el cnmp:i ra1il'O regional )' lenicndo en cuenm que la mayor canudad de denuncias tienen como lup;ar de origen: Urna.

\section{b. Marco Teórico Concepiual}

1.n Convención Interameri cana para Prevenir, Sancionar y Erradicar la violencia contra la Mujer ${ }^{1}$ ru:ificada por c:J Gobierno Peruano, rccom11ce la revicam1Z!IC1Ón como una forma de ,iolencia escrucrunl como se mdica en u Articulo 7:

a. "abs1encrse decualquieracción opráct1C11
cQnÍOrnudad con cst:1 ob! Jgac1on; (...)

d. adopta_r medidas 1urld1ca para coom111ar al :igresor a abstenerse de hougar.iminúdar, amenazar, dañar o poner en peligro la $\backslash \cdot 1$ da de la mujer de cualquier forma que atente contra su 1 mcgmlad o pcr.judiquc

su propu dacl; (...)

g. establecer los mcc:I11s111os judiciales y administrativos neces11rios para asegurll.f que la mujer objeto de l'JOlenoa tenga acceso efectivo a rcsarcunicn w, rcpa r:iclón del clañn u oiros medio de compcosaci6n jusm \ dicaces,"

Sobre esta base, el Articulo 2 de la C:onsa ruc1ón Poliúca d<.- Peni de 19!>3 las persona 1iencn como derechos funclamcn t:1lc:

"A la igualdad ante In ley.Nadie debe ser discriminado por mmivo de origen, raza, sexo, idioma, religión, opinión, conclición cconórruca o de cuak1u1cra otra indolc."

En es1c mismo sentido, el llrticulo 139 dc la Consárución, precis2 lo siguiente respecto del órgano Jurisdiccionlll :

'La observancia del debido proceso y la tutela jurisdiccional."

Al csrnblecer esms clercchns a nil'cl de tratado internacional radficado por el Perú y La Carra magna el Esmdo se oblign, 11 traves del mngo mñs airo, a l•clru- por su implcmen tnción, el derecho a un proceso justo, d derecho a ser proicgida como icóma, el derecho 11 no ser re,icámiuda de \'́́olcncia conr:ra la mujer y ,ciar por que las au1oodadcs, sus funcionarios, pcn;onal $y$ :igcotcs e insifrocinnes e comporten ele 
1 h11p/www.01 lorg/.,/nmccv1/doa/8demOoP•<••ESPANOL. pclf

h11pt//wwwn>nrg/J11r!dlco/•pmlsb/1ratadosla·6Lhlml en C.I sistema de admmisrfllclïn de jusac1a. Es asi como nos permmmos desagregar los deberes del Eslltdo:

1) Car.muzar el debido pnl <:csu to1uando en cuema Iru; desigualdades existentes (género, edad, discapacidnd, crnia, ecc.), y

2) Esmblece.r mtcar11s111os judíei:ue 4u,e tomen c:n cuenta las ncccsith1dcs de 1.odas 
las personas y que les procuren al menos la obtención de los siguientes derechos:

a) Ser parte del proceso judicial en condiciones de igualdad,

b) No ser revictimizadas en el proceso judicial,

c) Participar plenamente y comprender el proceso a seguir,

d) Contar con servlaos de administración justos, $y$

e) Gozar de información judicial que oriente a la usuaria para facilitar la toma de decisiones.

Es así como llegamos a la normativa interna peruana según el Código Penal Peruano, en su artículo $170^{\circ}$ original define Violación sexual como:

"El que, con violencia o grave amenaza, obliga a una persona a practicar el acto sexual u otro análogo".

Esta definición fue modificada por u n espacio ampliado por el Artículo modificado por el Artículo 1 de la Ley No 28251, publicada el 0806-2004 y vigente, el cual a la letra indica

' /que cols violencia ograve amenaza, obliga cs1110 persona a tener acceso camalpor vía vagi11al, anal o b11cal o realiza otros actos análogos introduciendo oijetos opartes del C11erpo por alg11na de las dos p111'Aeras vías"

Tradicionalmente en la legislación penal nacional se han tipificado tres modalidades de violación entre los delitos contra la libertad se\}'Ual2

Generalmente se asocia el abuso sexual únicamente con la violación sexual, esto no es

2 Según Acuerdo de Pleno Casatorio 01- 2-012/C]-116 a) La violación (strictu sensu) o acceso carnaJ con empleo de medios violentos (violencia física o amenaza); b) Las violaciones presuntas o supuestos donde el acceso carnal se califica como no consentido por el sujeto pasivo y por ende punible, mediante una presunción iuris et de iure; ye) La violación por prevalimiento o acceso camal mediante abuso de Ja posición de dominio y subordinación que ejerce el agente sobre la víctima. correcto ya gue existen muchas modalidades de abuso se'"-Ual como se detalla en el Acuerdo de Pleno Casatorio 01- 2012/CJ El contacto ñsico abusivo se puede dar de las siguientes maneras:

a. "Contactos bucales en zonas genitales u otras vinculadas a la actividad sexual y que suelen estar cubiertas por la ropa (pecho, vientre, pelvis y glúteos). Estos contactos pueden incluir besos y otras formas de gratificación oral corno lamer o morder.

b. Caricias, frotamientos o tocamientos de las zonas del cuerpo ya señaladas, con la finalidad de excitarse o explorar el cuerpo del o la menor de edad. Esto incluye la estimulación de los órganos sexuales del niño o niña. Igualmente, los frotamientos que la persona abusadora efectúa "como por descuido", o aprovechando situaciones en donde el cuerpo de Ja o el menor de edad es accesible, por ejemplo al pasar por un lugar estrecho, cuando se está en el microbús, cuando se comparte la misma cama, y aprmrechando situaciones de expresión de afecto.

c. Realización del acto sexual o coito, lo cual se denomina violación sexual. Esto puede darse mediante Ja penetración del pene en la vagina o en el ano. Incluye también la penetración con otras partes del cuerpo (los dedos) o con objetos. El denominado sexo oral también se ha definido como una modalidad de violación sexual.

d. El sexo interfemoral que consiste en la realización del acto sexual sin penetración. El órgano sexual masculino se excita por frotamiento entre las piernas de la o el menor de edad. Algunos abusadores suelen recurrir a este acto y evitar la penetr-ación que tiene penas de cárcel más severas."

Como hemos anotado, la afectación de derechos fundamentales se hace evidente, lo cual 
reafirmamos a partir de los sjguientes Tratados internacionales ratificados por el Estado Peruano. Conferencia Mundial en Viena en 1993, el acceso a la justicia se analiza desde la óptica de los Derechos Humanos; de ahi el eJ principio de que todo derecho fundamental debe interpretarse en forma progresiva. Así pues, el derecho humano establecido en el arúculo 8 de la Declaración Universal de Derechos Humanos del 10 de diciembre de 1948, ya no se puede considerar como el simple deber del Estado de proveer en abstracto un recurso ante los tribunales, sino de proveer efectividad:

" Toda prsolla fit111e derecho a $\mathrm{m} 1$ remrso efectivo a11te los 1Jib1111ales 11acio11ales co171petentes, q11e la ampare contra actos que violen s11s derechos fimdamfJ1/tales r11co11ocidos por la co11stit11ció11opor laly."

Consideramos que el acceso a la justiaa no es únicamente una mera declaración dela posibilidad, que tiene toda persona, de acudir al Poder Judicial; sino que es un derecho humano que involucra el deber estatal de proveer un servicio público ${ }^{3}$. Como derecho humano, el acceso a la justici::i debe ser un servicio público que el Estado debe garantizar a t0dos los habitantes de su territorio como se indica en la Declaración Universal de Derechos humanos:

"sin distinción alguna de raza, color, sexo, idioma, religión, opinión política o de cualguier otra índole; origen nacional o social, posición económica, nacuruento o cualquier otra condición."

3 A criterio de Gordillo. el seniicio público debe ser entendido como un servicio técnico prestado al público de una manera continua para la satisfacción de una necesidad pública y por una organización pública, para la satisfacción concreta de necesidades colectivas, y asegurada esa acción o prestación por el poder de policía en vista de dar satisfacción a una necesidad de interés general. Wase: http;/^vww.gordillo.cQm/pdf 1omo8/capítulol l.pdf

4 ArtjcuJo 2 de la Declaración Universal de Derechos Humanos.
Considero importante anotar que esta perspecriva de derecho fundamental debe ser analizada adicionalmen te a la l uz de los siguientes instrurnen tos:

La Declaración Universal de los Derechos Humanos. Como ya se dijo, este documento no sólo establece que su contenido se aplica a todos los seres humanos incondicionalmente "sin distinción alguna de raza, color, sexo idioma o cualquier otra condición"5, sino que además establece una serie de derechos relacionados con la administración de justicia como lo son:el derecho a un recurso efectivo ante tribunales competentes $<$, a no ser detenida arbicrariameote ${ }^{7}$, el derecho a la justicia en condiciones de igualdad $y$ el derecho a la presunción de inocencia ${ }^{11}$.

La Convención sobre la Eliminación de todas las Formas de Discrimin ación contra la Mujer enfaciíla la protección de las ciudadanas contra ciertos tipos de coerción realizados por el Estado. Eo su artículo segundo, inciso c) se señala el compromiso de los Estados Parte a "establecer la protección jurídica de los derechos de la mujer sobre una base de igualdad con los hombres y a garantizar, por conducto de los cribunales nacionales o competentes y de otras instituciones públicas, la procección efectiva de la muj er contra todo acto de discriminación".

El Pacto Internacional de Derechos Civiles y Políticos. En su artículo 2, establece que el Pei-ú se compromete a respetar y a garaoti7.ar a todas las personas que se encuemren en su territorio y• estén

\footnotetext{
5 ArtícuJo 2 Declaración Universal de Derechos Humanos

6 Artículo 8Declaración Universal de Derechos Humanos

7 Articulo 9 Declaración Universal de Derecho Humanos

8 Artículo LO Declaración Universal de Derechos Humanos
}

9 Articulo II Declaración Universal de Derechos Humanos 
sujetas a su jurisdicción, todos los derechos reconocidos en dicho Pacto, "sin distinción alguna de raza, color, sexo, idioma, religión, opiruón política o de otra índole, origen nacional o social, posición económica, nacimiento o cualquier otra conclición social". Reconoce, además, el derecho de contar con recursos judiciale $\mathrm{s}^{\text {'0 }} \mathrm{y}$ con una justicia pronta y cumplida en condiciones de igualdad ${ }^{11}$.

Declaración y Plataforma de acción de Beijín ${ }^{12}$ Resultados en Objetivo estratégico D.1 Adoptar medidas integradas para prevenir y eliminar la violencia contra la mujer. Medidas gue han de adoptar los gobiernos nos indica: "Ofrecer a las mujeres victimas de la vtolencia acceso a los sistemas judiciales y, según lo previsto eo las leyes nacional es, a soluciones justas y eficaces para reparar el daño de gue han sido objeto, e informarles acerca de su derecho a obtener compensación a través de esos mecanismos"

En este mismo sentido, el sistema interamericano de protección de los derechos humanos, también dispone derechos relaci onad os con el acceso a la justicia, tal como anotamos:

La Declaración Americana de los Derechos y Deberes del Hombre, establece el derecho de igualdad ante la ley en el artículo II: "Todas las personas son iguales ante la Ley y tienen los derechos y deberes consagrados en esta declaración sin distinción de raza, sexo, iclioma, credo ni otra alguna.". Y reconoce el "dered10 de justicia" en el artkulo \}'V III: "Toda

10 Articulo 2. inciso 3b "laautoridad competenrt:, judicial, admims. trativa o legislativa o cualquier otra autoridad competente prevista por el sistema legnl del Estado. decidirj sobre los derechos de toda persona que interponga tal recurso )'desarrollará las posibilidades de recursos judiciales.

11 Artículo 14.

12 b.Up://www2 .unwomcn.org/-/media/headquanersfattacbmeuts/ sectlons/cswlbpa s final web.pdf? $v=1 \& d$ 2Q160316Tl50755 persona puede acudir a los tribunales pata hacer valer sus derechos. Asimismo, debe disponer de un procedimiento sencíJlo y breYe por el cualla justicia lo ampare contra actos de la autoridad queviolen, en prejuício suyo, alguno de los derechos fundamentales consagrados constitucionalmente".

\section{La Convención Americana de Derechos} Humanos establece en su artículo 1 que: "los Estados Partes en esta Convención se comprometen a respetar los derech os y libertades reconocidos en ella y a garantizar su libre $\Gamma$ pleno ejercicio a toda persona que esté sujeta a su jurisdicción, sin discricrúnación alguna por motivos de ra7.a, color, se:xo, idioma, religión, opiniones poüticas o de cualguier otra índole, origen nacional o social, posición económica, nacimiento o cualquier otra condición social". Reconoce las garantías judicfales en el artículo $8_{1}$ el principio de legalida $<$ l y de retroactividad en el artículo 9, el derecho a indemnización en el artículo 10,la igualdad ante la ley en el articulo 24 y la protección judicial en el artículo 25. Asimismo, el Protocolo de esta misma convención (el Protocolo de San Salvador) en su artícu lo 3, establece el derecho a la no discrimi nación de la siguiente manera: "los Estados partes en el presente Protocolo se comprometen a garantizar el ejercicio de los derechos que en él se enuncian, sin discriminación algu na por motivos de raza, color, sexo, idioma, religión, opiniones políticas o de cualq uier Otra índole, 01gen nacional o social, posición económica, nacimiento o cualquier otra condición social".

\section{La Convención Interamericana para}

Prevenir, Sancionar y Erradicar la Violencia contra la Mujer establece en su artículo séptimo,incisos d, f, y g, las sigllientes obligaciones de los Estados Parte: "d) adoptnr Jas medidas jurídicas para conminar 
al agresor a abstenerse de hostigar, intimidar, amenazar\} dañar o poner en peligro lavida de la mujer de cualquier forma gue atente contra su integridad o perjudique su propiedad; f) establecer procedimientos legales justos $\mathrm{y}$ eficaces para la mujer que haya sido sometida a violencia, que incluyan, entre otros, medidas de protección, un juicio oportuno y el acceso efectivo a tales procedimientos y g) establecer los mecanismos judiciales y admirústtativos necesarios para asegurar que la mujer objeto de violencia tenga acceso efectivo a resarcimjento, reparación del daño u otros medios de compensación justos y eficaces.".

\section{Objetivos}

El objetivo central de la presente investigación es generar propuestas de mejora en el ámbito de acción de una denuncia penal por violación sexual a las mujeres en Lima, a fin que estas propuestas puedan ser recogidas como parte de una estrategia de transversalización de género en el que se denote una Política de Estado que garantice el debido proceso y evite la re victimización de la agraviada.

La investigación tiene como objetivo servir de linea de base para futuros informes más amplios sobre violencia de género, en particular sobre violencia sexual.

Finalmente, la investigación tiene por objeto sensibilizar al lector respecto de las dificultades asociadas a la realización del trámite de la denuncia.

\section{Metodología}

Se realizó el traba jo de investigación con una metodología cualitativa, con ética acorde al tema trabajado para la realización del presente informe.

Iniciamos con una etapa descriptiva de la información documental que hemos detallado y que se encuentran contenidos en la bibliografía, realizando un análisis apropiado para poder atender el problema planteado. Demostrando la vulneración de derechos constitucionales de debido proceso e igualdad ante la ley para el acceso de la justicia con el trámite actual realizado.

Setomó encuenta eldetalle presupuesta! delos portales de Transparencia del MEF y i $\backslash$ IIMP, para el desarrollo de las recomendaciones.

Adicionalmente nos permitimos indicar que pese a haber realizado algunas entrevistas a diferentes actores con criterios de investigación, no se nos ha autorizado la divulgación de resultados, principalmente frente a médicos legistas que precisaban gue no cuentan con herramientas de trabajo suficiente y el envío de realización de análisis, por razones de represalia que podrían tomar sus superiores. Sin embargo, hemos suplido estas entrevistas con el análisis documental donde hemos detallado la visita inopinada del propio Fiscal de la Nación durante el presente año que evidencia la falta de equipo $y$ ambiente adecuado de trabajo del Instituto de Medicina Legal.

Finalmente, como se expuso en el prefacio del presente documento, la investigación, que responde a una vivencia particular, llevó a plantear la hipótesis de revisión si se trataba de un único caso aislado o si las víctimas cuentan con el procedimiento descrito como regular para la realización del trámite de denuncia penal por violación.

\section{Resultados}

En el desarrollo de la presen te investigación, hemos demostrado la vulneración de derechos hacia la víctima deviolación sexual, contradiciendo los derechos fundamentales precisados en los Tratados internacionales suscritos por el Estado 
Peruano y la Constitución Política del Perú, según hemos detallado.

En este sentido consideramos importante precisar la necesidad de:

A) No Revictimiz ación , en el sentido de evitar toda acción u omisión relacionada con el sistema judicial que atañe los derechos fundamentales de la víctima que acuden al sistema en búsqueda dela justicia; considerando adicionalmente que esta afectación implica también la vulneración a la dignidad humana.

Cabe anotar que en las etapas planteadas la víctima debe repetir la historia desde la anotación de la denuncia en la comisa.ria correspondiente, luego al dirigirse hacia el médico legista, que debe reconocer los hechos para realizar inspecciones físicas adicionales; en este mismo sentido, al realizar los análisis adicionales y el peritaje psicológico.

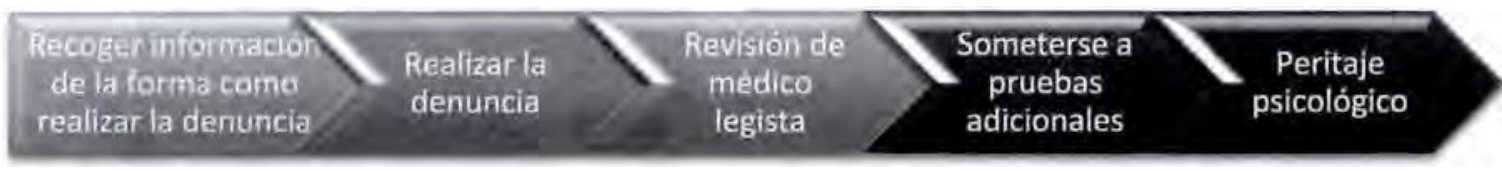

Como anotamos en nuestro cuadro detalle del flujo regular del proceso, el primer paso de recoger la información para poder realizar la denuncia también pane de la víctima quien tiene que comentar lo acontecido.

En este sentido, demostramos que con el proceso actual la víctima debe manifestar lo ocurrido en hasta cinco oportunidades diferentes, luego de lo cual también se puede producir que a nivel de fiscalía o judicial se solicite una nueva audiencia en la que se requiera la manifestación de la víctima.

B) Debido Proceso, la afectación al derecho a trámite al que debe recurrir la víctima regulado por la ley formal, debe establecer una serie de garantías tendientes a proteger a la persona humana frente a la arbitrariedad y el error.

Nos cuestionamos a lo largo dela investigación si se trata de una arbitrariedad el traslado de la victima en diversas sedes para poder culminar el proceso de denuncia. Y la respuesta formal es que se responde a una ponderación preliminar; es decir la mayoría de denuncias formales tienen víctimas a niños y adolescentes (quienes tienen prioridad y mayor asignación de recursos). Siendo que hablamos de un porcenta je de alrededor de $80 \%$ de la total idad de casos, parece prnden te afirmar qLle "los otros casos" (es decir, la atención a la denw1cia de una vjolación sexual cuya víctima es una mujer) pertenece a menos del 20\%. Ello) a su vez aduciendo, que los recursos se deben repartir ptimero en poblaciones vulnerables, como contemplamos en el presupuesto.

C) Acceso a la Justicia, la posibilidad de acceso a todos los beneficios y facilidades de Ja justicia por parte de todos los seres humanos se ve claramente reducida. Pues al colocar hasta cinco estadios para tramitar una denuncia penal por violación sexual, corresponde cuestionarse respecto del acceso a la justicia que tiene la víctima. Más aún en los casos de provincia; nótese que hemos realizado el presente análisis en la capital a fin de evidenciar las deficiencias del proceso pero, por sobre todo) dejar en sobre aviso que el menor nivel de acceso se encuentra en las zonas rurales y periu rbanas de nuestras regiones.

D) Asistencia a la víctima . Las víctimas deben recibir una asistencia material, médica, psicológica y hasta social de ser necesario, por conducto de los medios gubernamentales. Atendiendo ello, como parte de Ja investigación entrevistamos a algunos psicólogos dínicos especialistas en 
esta 1m teria y particulannen te $I M$ resultados resultaron sorprendentes pues afirman que el soporte psjcológico coa que debe comar la victima, dependiendo de cada caso, l leg mayorita ria111cn tc a una tcn1pia de pot vida. Ello lleva nueVunen te a ct:l.esrionar respecto de la capacidad e\$tara l ele pcider atender estos ca. O y nuestra respuesta va hacia Ja prevención priorira jamence y e.o el esradio exportde J os hechos. tm oportt: deasocincione pt•blic::o pavadas. para poder dar a la ,frtima una calidad de asistencia.

E) Concentración de trámite. Considero que las accuaciones deben realizarse en el menor número de actos posibles, los cuales deben ser cuntinuo; las cinto etapa del proceso resultall un exceso en tndn senr:irln para pnd er abordar la denuncia penal de viólaci6n sexual.

I3| mejor supuesto que encontramos c11 derecho comparado para la atención inmediata de Ju víctim1 es I través dc las cámaras Gcsscl, como hc.rrnmieJta pa ta evitar la re vktimi.lładón, conseguir una concentración adecuada Je rriimite y sul> ré todo de acceso a la jus ticia a 1r:Jvés de un dculdo proceso.

Sin emba,rgo, reconocemos el alto costo asociado a la implementación deer:.is herramicn tn. En este scncidt>, anotmnus el c.xpedic.nLe al 9ue h(Jmoi; temdu alccs $\mathrm{C} \backslash$ para. la cnotrnación el e esrn herr:urucn ta en Ucarali. Atendiendo sin eluda a la t ta ta tle menores de edad y la 1.1ecesidad de contar con esta herramienta en la zona. S/ . 4-3,548.00 (Cuarenta )' Tres Mil Quinie.ncos Cuarenta y Otho con 00/100 Nuewis Soles) 1 prol>aci.ón de Expudiente e.le Contratació.n ${ }^{11}$ Sin embargo,

B l '. ADS·"Adquisídó11 de.Equipos y Mobllinrio paro la lmlement щң: :iñn de 1-a Snl de Bntrcvi t:i Ún1cn Cú1ncaril Gc."Sdl D IL 11 U.A\'Alf' RP.F ,hfornic N" 395-D12-Ml'FNGG.GJ!CLOG GEA h1,p://YYCbc: jcht gtwgh::uscrconlt:nt co1n/aea reb?9 (hcitUp://

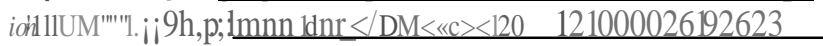
:18@rodUZAAB.pd( revismnos las conrrat:1ciom:5 en otros paisc <le L;1ti11ou nériCl1 cu)CJ costo tm menor en Llfl 20% como es el caso de Bolivia"'- Por In que tambié11 resultn celevaote las condiciones de cootracación, en la que podemos asumir la complejidad de nccesos en Ucllyali, enrre otros factores.

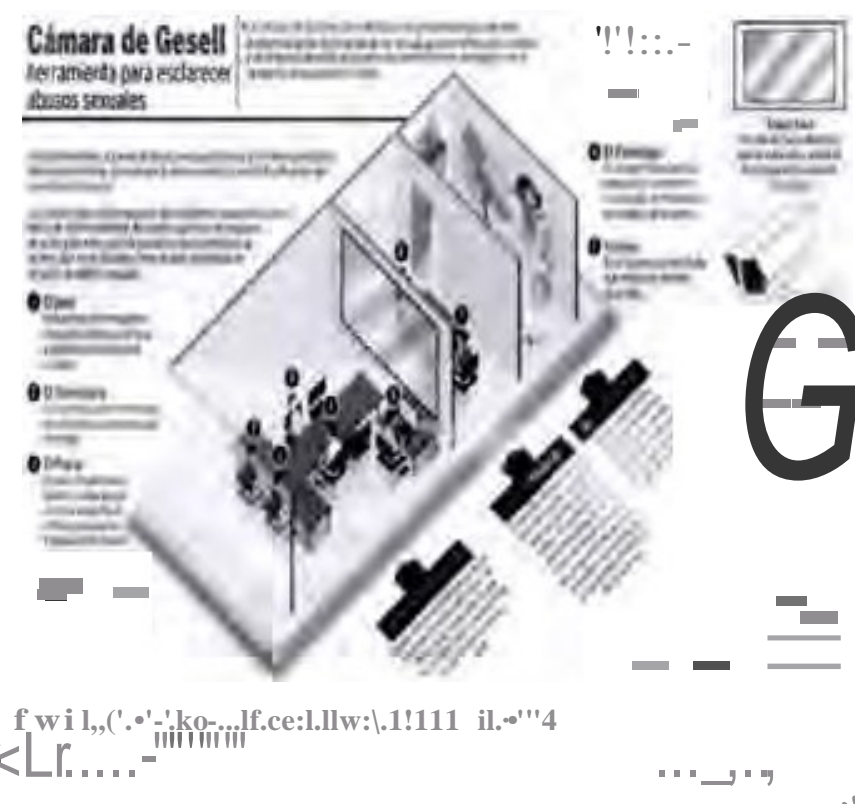

III. Htt.*):""1 Ic...';1.C11...-;J..-Wkf!lfl 14fl', *

Tpmnlarrqcom e1M...111.iJoi<。 f-4tUll in'1 Sln emi'Ai:go, en el Perú existcn también ,1 "salas de entre'\Sta única"15 que a difcrcncia de las cámara GeseU, estas salas no tiLmn un vidiio espejado, por lo que su implummtadóo sude cosmr $\mathrm{S} / 1 \mathrm{O}$ mil.En este sentido una de mKlitms propuestas dececomcndacióo está enaceodc.r otrosistema simfütr de bajo costo parn podet atender eticie.ntememe una denuncia penal por \folación sexual.

Todo lo planteado refiere 1 derechos vulncmtdos hacia la vkuma; sin embugo, no olv1tfa.mos la ponderación haei:1 lo\$ derechos tlel acusado quien $\mathrm{k}$ corresponde un siluación

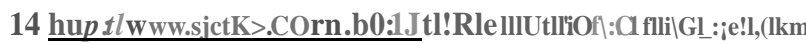
c11Lii1...dcparramcn13l.dc).-bcni ·lct22Q264.html

15 h1p/für $<$ p11bli<11.pellmpWJl/socied •di808188-<>m•ca-G «llun-.1 mbirnrc-ap«ínl dondr-la·vis: tin1a-hublu-dr!.tu1uma suCr1 iJ.ii 
de Inocencia, el no ser cratado como culpable mien tras no haya en su contra una sentencia conclusiva firme. Así como el "IN DUBIO PRO REO" lo cual lmpLica que Ja conyicción del juez respecto de la culpabilidad del imputado debe superar cualqujer duda razonable, de manera que cualquícra gue exista obliga a fallar a su fayor, deberá tomarse en cuenta este principio en la valoración de la prueba que se obtenga de la diligencia.
Respecto de la implementación de políticas de Estado para lograr la eficiencia en el proceso descrito debemos anotar que el plan nacional contra la violencia de Género de 2016 al 2021 cuenta con un enfoque de Género que pone en eYidencia las desigualdades sociales y relaciones asimétricas entre hombres y mujeres; así también cuenta con un enfoque de derechos humanos, en el gue se establece gue son inherentes a las personas se centran en la dignidad intrínseca y son inalienables.

\section{Inversión pública gobierno central}

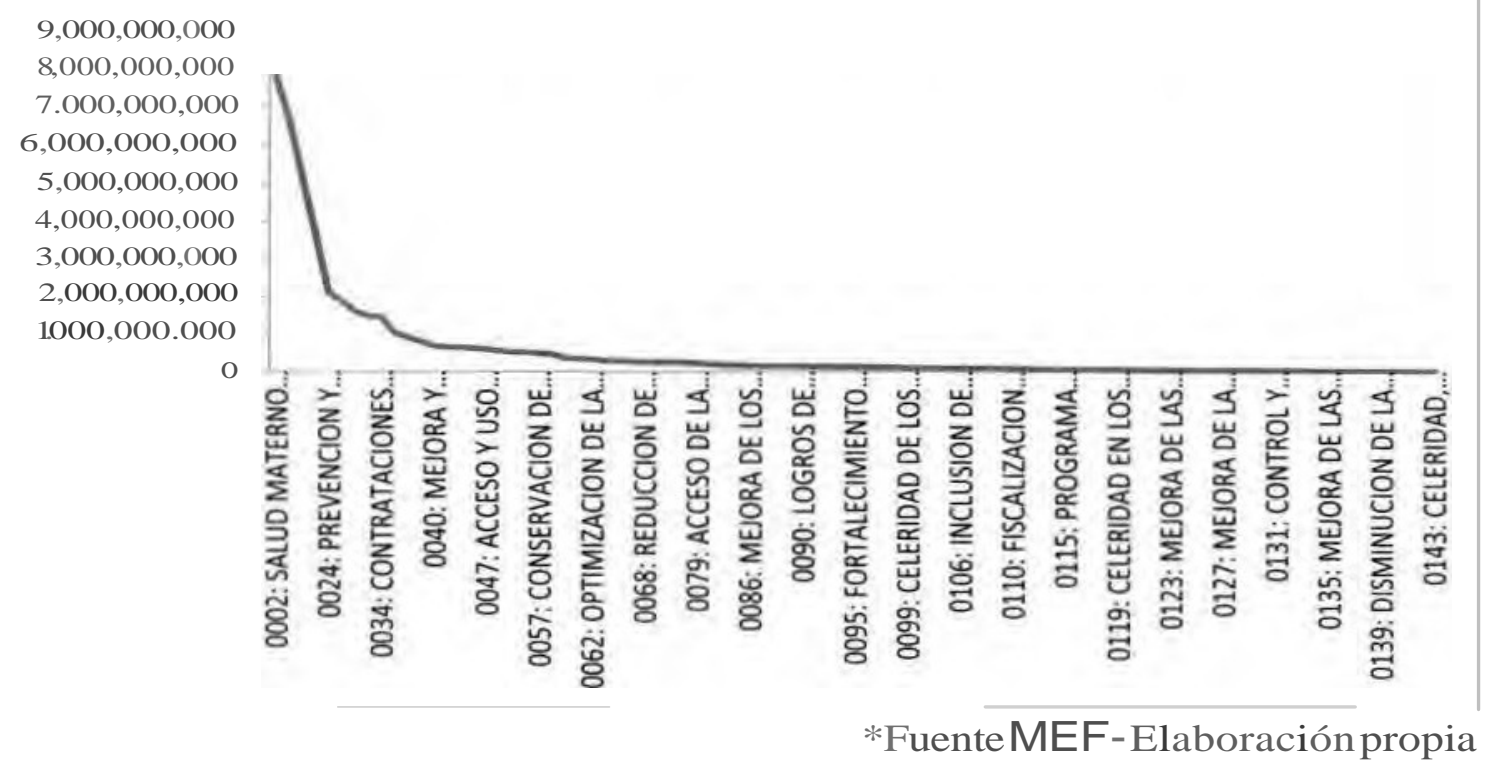

Como apreciamos el gasto púbLico prioritario no reAeja el tema materia de nuestra inYestigación. Por lo que verificand o el detalle de las partid as solo encomramos dos únicas que podrían reflejar lo que hemos planteado: Celeridad en procesos judiciales de Familia v Lucha contra la $\backslash \cdot$ iolencia familiar. Cabe anotar que los montos indicados son reflejados a nivel nacional, con lo cual se diluye mucho más el ámbito de acción.

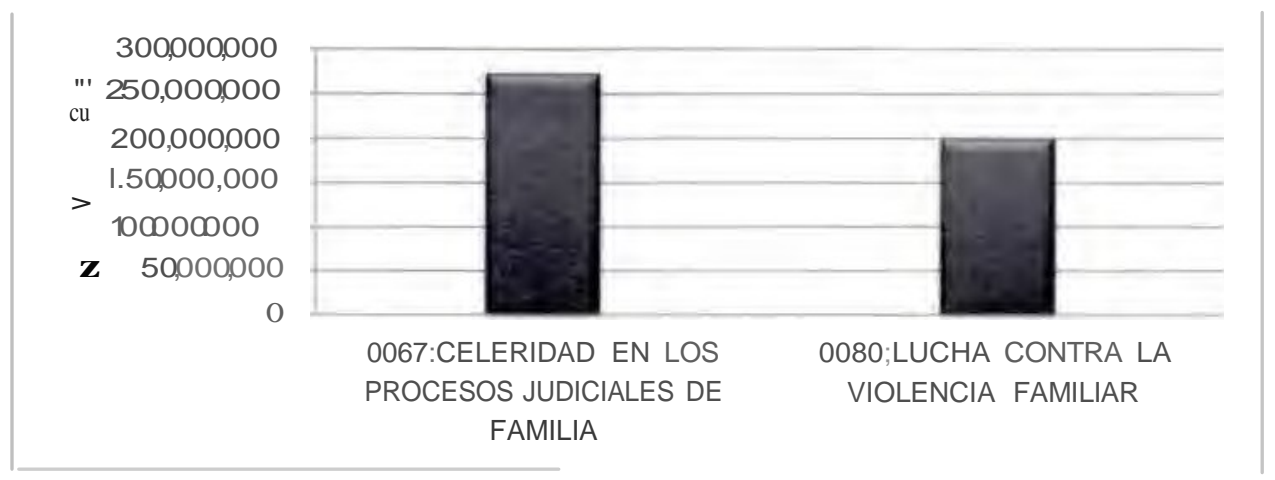

*Fuente 1ffiF - Elaboración propia 
Como reconocemos, no es posible trabajar una políúca publica sin asignación de presupuero; sobre el particular me permi to reAcxionar sobre un:1 butina plúctica. generad;1 en Colombrn ${ }^{16}$ que pretende fortalecer agenda de desa rrollo sotenible, igualdad de género y empoderamien ro de la. mujeres el Plan nacional de desarrollo de Colombia, esmblece lit creacion de un mecanismo i ntctinStin1cionaJ parn la integración de la inclusión de género en el presupuesto.
EIEstadoqueda comogarantedederechoscn esta nueva pcrspeccivn, en la cual se establece lin presupuesto especifico para las ađividades dt: trnnsvcrsalizar c:l enfoc.jue de genero en tódos los áSpecros, pues reconoce que las Polftic- IS pá blicas sin presupuesto no tienen ningún alonce.

Ahora bien, pese a la percepción general de no conai.r con comisañ $<\mathrm{L}<$ implementad $<\mathrm{L}<$ a nivel nncionaJ, las cstadístic lls de IN El nos brindan in formación diferenie'

RAFICQ 11" 71

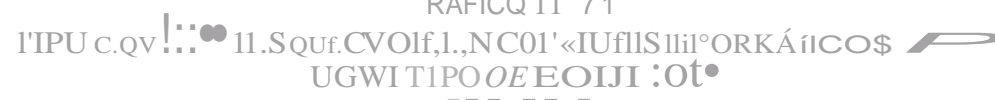

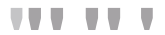
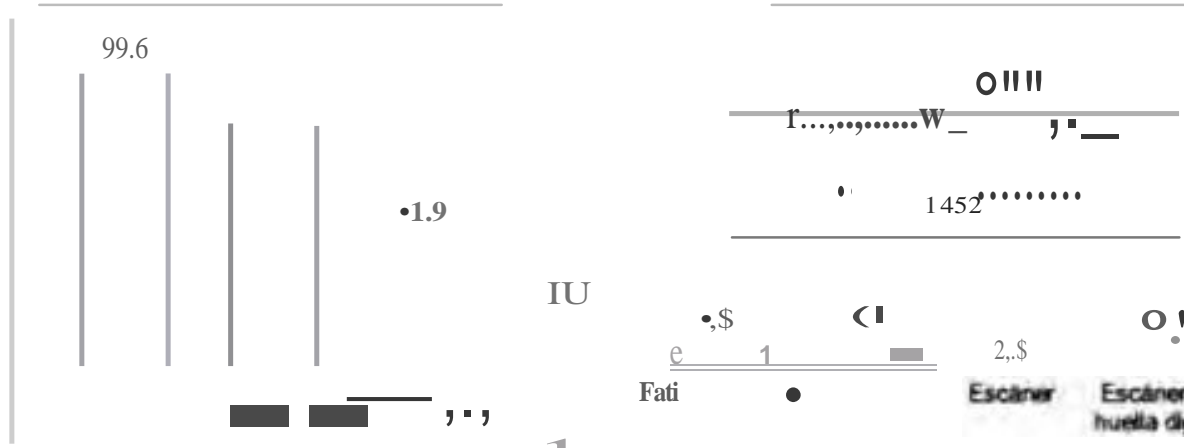

IU
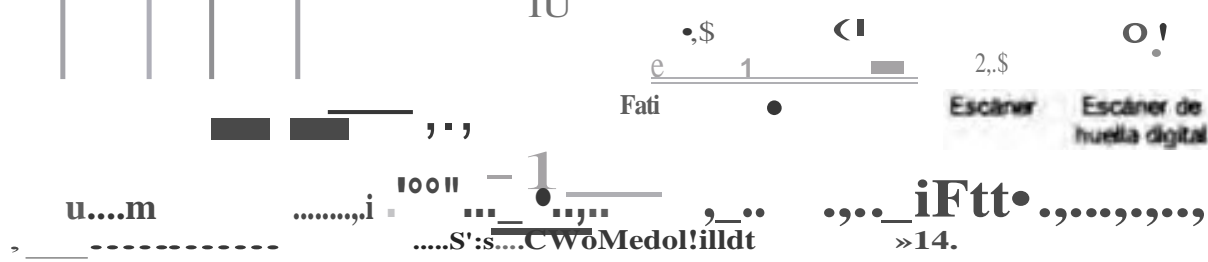
.........,. $\mathrm{i}$

10011 -
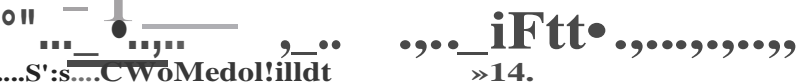

'Plleoto INE!

i'E COMISARIAti OUECUE»TAH C:ON EOUJi>OS thFOIUMTICOS f ROPIOS. 2014 t.4txol11to y porcenuio)

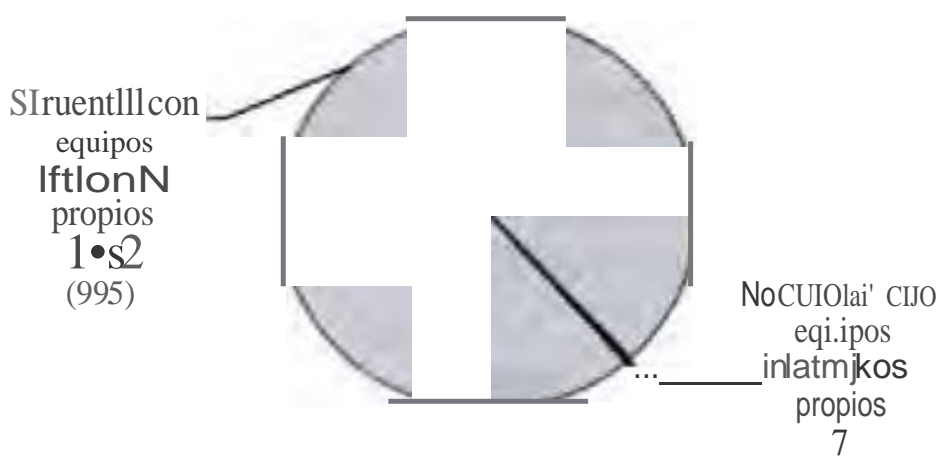

$(0.5)$

*Fuente: NE!

IG A rt 1 q do la 1 y 17S3dt 201 d;I PNn (1014-201) -Todo• por un Nucvu P.b y-aJ Conpe"' Social $t f>I$ •Et.1u1d1.1d de Gt:-nero P'Jm HS MIljNke

h1tp//^!'W1'.UOII'Omtl).otg/c\&/dfgiral Jlbrnc)'Ivjdwsfyidcojd ys11 dS<lh?rf:Istb?Sh.3»•S)'1al1.dpuí

ti hUÜ"r"Jii i. 9b.p/ㅌ_1t<!l111.M•nu Rccu rsiro/publl,Q.CúlJ:Itt. digit.JCi/E.!/L!b 1254/Jjbm pdf 
En este sentido, podciamos también anotar IIIIC fuera pusibk implcmc.:1 1tarsistem as de circu1to ce(rado o inrrane' a fin de brindar informadón preliminar a la victima, un chat con línea 100 , por ejemplo; ya que en el mejor escena rio tendñamos una implementación completa de las comisarias para puder a'ender mejor a las victimas.

Sin embargo, en el docu men to tle Pl.tn Nacional contra la violencia de Género en la quese precisa como objetivo "Garantizar a las personas afectadas poc la violencia de género, que perjudica priocipalmeme a las mujeres en sll diversidad, el acceso a servicios in tcgrnle, \{!!tkulados, oporttuius )'de calidad, dei;tinarlos a la protección, atención, recuperación de la personas afectadas, así como la sanción y reeducación a las per.;ona.'agresoras.

A través de Ja Implementación de un proceso integral y articulado de prelención, atene1on, proteccton y recu peración de personas afectadas y sinción y reeducación di: personas agresoras." Si bien se establecen cVmo t"spunsables el MTMl', flNINTER, .l' P, PJ, ÑllNSA, MINJ US. MINEDU, UGEL, DR.E. MJN INTER-PNP. MP, PJ, Gobierno Regionales DIRESJ $\backslash$, solo se especifica los reporres de implementnción del protocolo base $<$ le actuación conju n t;;; más nu se hace rcfercncJa a presupues to público establecido.

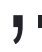

\section{0}

00100

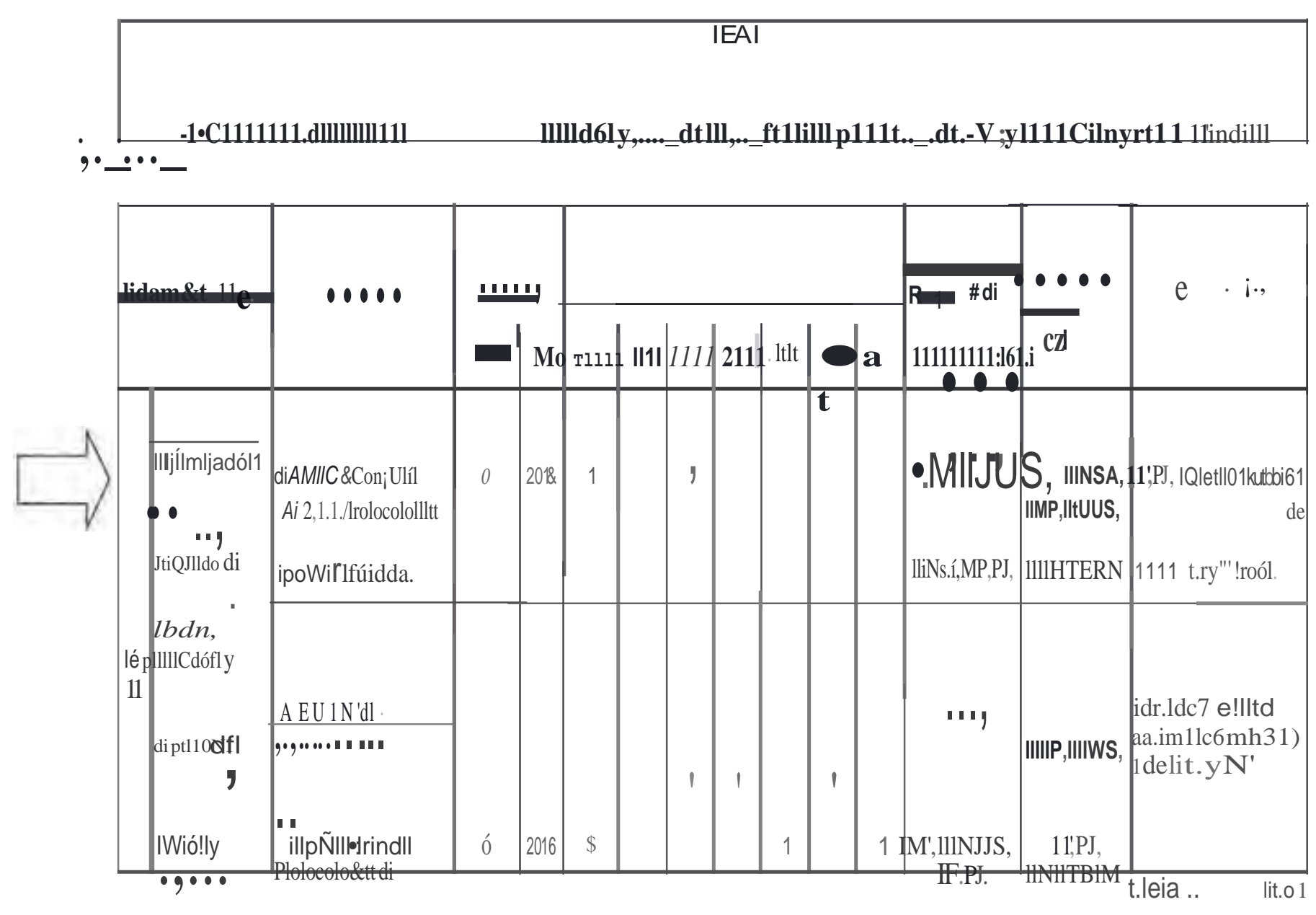


*Fuente:Mll\11' - Plan nacional contra la violencia de Género de 2016 al 2021

Luego de revisado el documento verifimmos en nc.gutl'a de re.cursos hacfa la prcvt•nc1ón de el 'Pr>ttal de tranpa tencia si exlstfa infnnnaoón lioleocia. Si bien se trata de periodos an 1etiotcs pnsre1iot a asignación diferenciada tle recursos, considemmos relevante :tnali?.ar la situación y la mi ma que aún no se encuen rra a disposición ponderar en mayor ptopmción los espacios dedel público: sin embargo, ubicamos una tendencia prevención. 


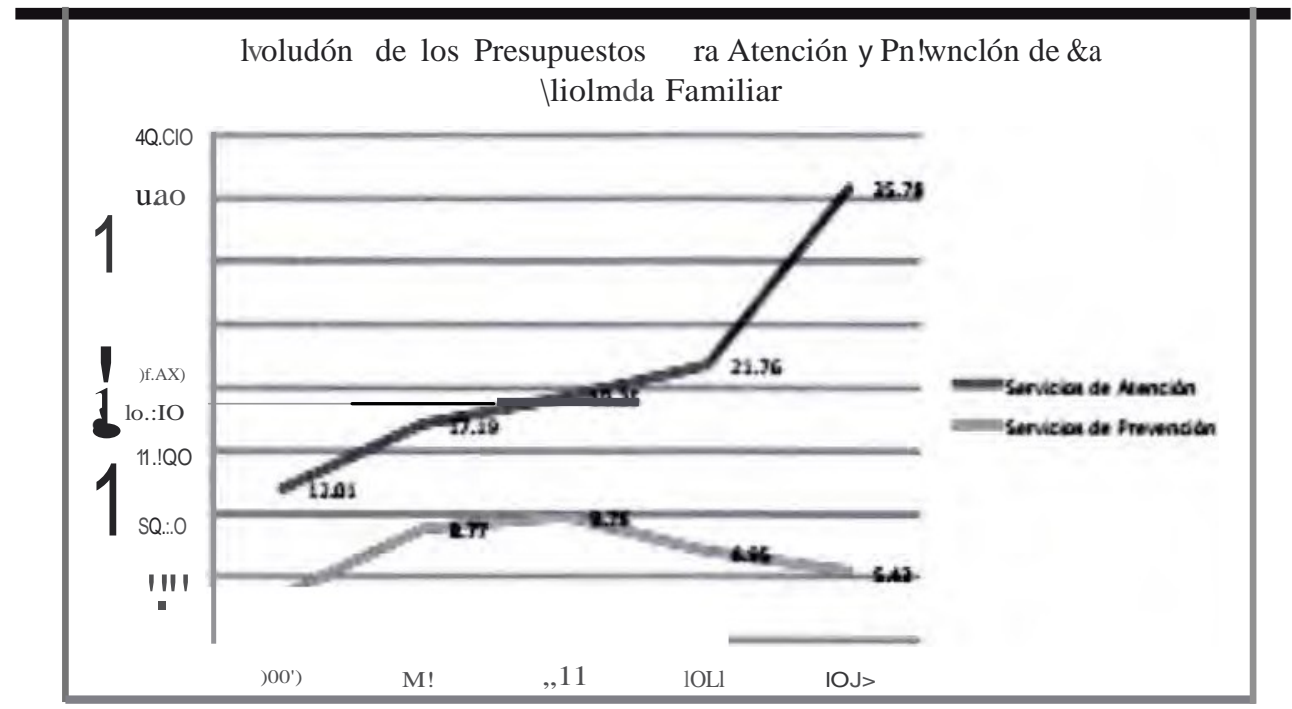

Pllra lo'años 2011y 201Jcxiste uru I!Jl3 : :itea'd;i en b Wo1 !!!cr\&imiento de I.IJ ilSign.iciola ;R51-1luest1rius

rtiAca::ines Comurcsilltt:s nocor.si8"fild11

*Fuente: DEMUS

Si bien el cuadro nos muestra un detalle de violencia familiar, no podemos dejar de lado el espacio de violencia hacia las mujeres, materia del presente estudio.

\section{Conclusiones}

1. Existe un espacio de mejo ra para el desarrollo efidcnte de un proceso de denuncia penal en caso de violación sexual a un a muj er en Jjma.

2. El proceso actual de denu ncia responde a cinco etapas, en diferentes espacios físicos en los que la víctima debe permanecer en el estado posterior a la violación; esto implica, sin poder ingerir alimento, ni higienizarse. Por ej emplo:

a. Conocimjento de la víctima de los trámi tes a reali zar.

b. Declaración inicial para asentar la denuncia ante la Comisaria oJ uez de paz

c. Examen médico legista

d. Análisis adicionales para toma de muestras

e. Peritaje psicológico

3. El tramite y conespondicntes actos de arbitrariedad a las que se somete a la víctima para la generación de la denuncia vulneran principalmente los derechos fundamentales recogidos en la Carta Magna y tratados internacionales:
a. Igualdad ante 11. ley
b. Debidoproceso
c. Dignidad de la persona

4. Existen un sin número de agresiones sexuales que no son evidenciadas en denuncias. Por lo que el número de denu ncias realizadas por m t1jcres aparenta ser considerablemen te menor al de ni ñosy adolescentes.

5. Como consecuencia de ponderación de la balanza, e1 Gobierno Central asigna recu rsos atendiendo prjoridades urgentes e inmediatas; dejando de lado casos como el plan teado pese a la evidente vulneración de derechos fundamentales.

6. Se propone:

a. Generar mayor acceso a información, como medida prcven tia necesaria para sensibilización de estos aspectos contra la Yiolencia hacia las mujeres.

b. Utilizar elementos de grabación para evitar la revictimización

c. Destinar recursos económicos hacia la 
capacitac1on del personal de atenc1on is compra de insumos para tomar las muestras necesarias en un mismo momento.

\section{Recomendacione s}

El espacio de innovación querequerimos para procurar u na mejora en elproceso dedenunciaspara atencjón de casos de violación se:l-. ual para mujeres, nos lleva a pensar en herramientas tecnológicas çue, m ás allá de ser costosas, no simplificatían necesariamen te el trámi te a seguir y se mantendría Ja vulneración de derechos planteada. En este sentido nos permüirnos anotar tres recomendaciones ciue :i nuestro criterio reAejan el enfoque de género y el enfoque de derechos humanos que propugna el Plan nacional, por lo que esperamos quepuedan ser implementadas como polirica de Estado:

\section{Generar mayor acceso a} información, como medida preventiva necesaria para sensibilización de estos aspectos contra la violencia hacia las mujeres .

$r$,a asimetría informativa juega un rol importante al momento de realizar la denuncia, más aón teniendo en cuenta el momen to de crisis interno de la victi ma. Es pot ello que incidimos en la necesidad de trabajar en largo plazo, con espacios de sensibili7.ación, capacitaciones; donde jueguen un rol importn nte la sociedad civil a través de las ONG y las Inscinacioncs Educaúvas como Universidades, Insónams, Colegios, etc.

En este sentido, se propone generar un plan de acción dosificado con meras asociadas al número de personas capaciradas, integrando factores de liderazgo y empoderamicnto femenino necesarios para mantener un espacio de conocimientos necesarios sobre la materia.

Nos preocupa la tendencia a disminuir eJ presupuesto en cuanto a prevención de la violencia hacia las 1111.1jeres ciue hemos detalJ ado; sin embargo reconocemos el rol Estatal y sobte todo las di, ersas necesidades urgen tes para lograr sobrellevar casos pu ntuales. Es por ello <lue incidimos en la necesidad de realizar cadenas de valor con ouos organismos, públicos y privados que puedan llelar este espacio de sensibilización procu rando trabajar en la prevención.

2. Utilizar elementos de grabación alternativos para evitar la revictimización

Nuestro escenario ideal setía colocar cámaras Gesell en todas las comisarías a nivel nacional, con lo cual la respuesta clara seria la falta de recursos; sin embargo, ya en Lima se han establecidos "salas de entrevista única" donde se puede contar con un espacio asignado para poder Uevar a cabo la entre, sra con la l'íctima.

Un buen espacio cjue podría asemejarse a los de las salas únicas son los espacios donde se realiza investigación de mercado, una sala sellada para trabajos de entrevistas a profundidad y focos groups con los gue se podría asociar a espacios académicos o las empresas encuestadoras de mercados como Ipsos A poyo ${ }^{18}$.

Sobre el particular, con siderarnos importante resaltar la posi bilidad de realizar asociaciones público-privadas en pro detrabajo deresponsabiJklad social, considerando inicialmente trabajos piloto y atenrueodo la cercanía y accesos para Jas Yíctimas y con contratos de confidencialidad necesarios. Podrían brindar los espacios en usufructo de manera temporal, por ejemplo.

Nuestro objetivo se manriene en hacer menos engorroso el trámfre de denuncia para la dccima, resguardando sus derechos de acceso a la justióa y debido proceso.

3.Destinar recursos económicos hacia:

a) Capacitación del personal de atención, y

b) Compra de insumos para tornar las muestras necesarias en un mismo momento.

$18 \mathrm{http} / /$ www.ipsos.pe/Ipsos Marketing Expertise 


\section{UNTFÉ-EPG}

$\mathrm{N}$ uevamente reiteramos que una estrategia de en foque de género y de(echos humanos no es posible si no le asignarnos recursos, en este sentido consideramos necesaria la capacitación al personal de atención, púncipalmente, en Servicio al cliente, aun cuando suene- extraüo, el poder trabajar como tm espacio de servicio púbU co puede generar mejoras com probadas, la capacitación sugerida es respecto de los siguientes aspectos:

,/ Entrevi tar a solas a la víctima. Validar las necesidades de Ja persona.

./ Establecer un ambiente de seguridad y con6anza

,/ Asegura de privacidad y confidencialidad

,/ Ser receptivo y empático. Desarrollar una buena comunicación con la perwna

./ Proporcionarle apoyo.Validar las estra tegias de supervivencia dela persona

,/ No minimizar,negarnijustificar lavioleocia

./ Revisar la lista de indicadores de violencia

,/ Registrarloshechos relevantes delepisodio de violencia:

,/ Guardar cuakpier evidencia Gsica tic la violencia (ropa, cabellos, semen, etc.)

./ Ayudar a Ja persona a desarrollar relaciones qllc la apoyen en el ámbi to afectivo

./ Dar a conocer las instancias de referencia y apoyo existentes

./ Ofrecer a la persona las alternativas con las que cuenta:

- Atención médica

- Atención psicológica individual

- Apoyo social

- Asistencia jurídica

- Medidas ele protección qlle puede gozar

- Grupos ele apoyo existentes en la comunidad

De igual manera implementar en los mismos espacios de atención dd médico legisla, la posibilidad de contar con prioridad de atención frente a otras personas que por otros motivos se encuentrnn también en espera. En este sentido, facilitarles las herramientas necesarias para que puedan tomar alli mismo las mues tras que fueran necesarias para contribuir a la deouncia, evitando el traslado a otro lugar a las personas.

Un espacio válido ta mbién pod ría ser trabaja r con los cenri:os méd i cos especializados para apoyo directo de la víctima, Ja atención del médico en emergencia fungiría como declaración jurada de lo acontecido.

Reconocemos que pueden existfr muchos otros aspectos de mejor.a, taoto al momenro de la denuncia como el proceso penal en sí mismo; sin embargo, rei teramos que el presente informe responde a un planteamiento inicial de an:ilisis y espernmos poder mantener el espacio abier10 pa ra contribuir en materia de mejora constante en función de un enfoque de género en las políticas públicas en general.

\section{Vil. Bibliografía}

- Constitución Politica del Perú

- Código Penal y normas conexas

- Código Procesal Penal

- Ley General de Salud

- Lt:y No 27115, Ley que establece la accióo penal pública en los delitos concra la libertad sexual.

- Ley N 29414 LC)' que establece los derechos de las personas usuarios de los servicios de salud, y modifica Ja Ley general de salud

- Decreto Su premo N" 008-2016-MIMP Decreto Supremo que aprueba el "Plan Nacional Contra la Violencia de Género 2016-202'1"

DEMUS (2013) "Seguimien to a los presupuestos asignados al programa nacional comra la violencia familiar y sexual y al plan nacional contra la violencia hacia la mujer por el Ministerio de la Mujer y poblaciones vulnerables y Otros sectores involucrados." 
Ulfe C. Tecnología que evita la revicti.mización en niños, niñas y adolescentes: Cámara Gesell vol. 2. Julio-diciembre: Hamut'ay 2015. Lima-Perú

Viviano, T. (2012). Abuso Sexual: Estadísticas para la reflexión y pautas para la prevención. Programa Nacional contra la Violencia Familiary Seh-ual.

Sitios web:

h tt p:/ / www.oas.org/ es / m e secvi/ convencion .asp

b ttp:/ / elcom erci o.pe/ sociedad / lima/ falta-persona l-usar-camaras-gesell-casosviolacion-noticia-1843516

h t tp: / / www 2.la te ch.edu / -box/ a se/ papers201 1/Anh.-unda_termpaper. PDF

h ttp :/ / cen trodein novacion. u c.cl/wp conteot/ uploads/2015/05/ el_paradigma_ de_la_t_grande.pd $f$

http:/ /www.rnpfn.gob.pe/ index.

php?K=364\&id=1200

http:// www.rrump.gob.pe/fües/

direcciones/dgignd/planes/ plaa-nacional-

igualdad-genero-20 12-2017.pdf

http:/ /www.inei.gob.pe/ prensa/ noticias/

el-301-de-la-poblacion-de-15-y-mas-

anos-de-edad-fue-victim a-de-un-hecho-

delictivo-8499/

http:/ / www.oas.org/ es/ mesecvi / docs /

Belem DoPara-ESPANOL.pdf

ht tp: / / www.oas.org/ ju ri di co/ spanish / tratados/a-61.html

h ttp:/ / www.gordillo .com/pdf_tomo8/ capitulo 11 pdf

h t tp: / / ww w 2 . u nw o men .org/ -/ m edia / h ead guarters / a t ta ch m en ts / sectj on s/ c sw / b pa_s_f inal_web. pdf $? \mathrm{v}=1 \& \mathrm{~d}=20160316 \mathrm{~T} 150755$

http:/ /webcache.googleuse rcon tent.com / search?q =cache $:$ http:/ / zonasegura.seace. gobpe/mon/docs/procesos/ 2012/000026 /926234808radD7AAB. pd $f$

h t tp:// w w w. sicoes.eom.bo/ implemen tacioo-camara-gesellen-fiscalia departamental-del-beni -lct220264.html h t tp:/ / larepublica.pe/impresa/ soci eda d / 808188 -cam ar a -gese U- unambiente-especial-donde-la-victima-habladel-trauma -sufrido h ttp:/ /www.unwomen.org/es/digitallibrat:y/videos?yjdeoi d=y5IjdSQh9r E\#stha sh.3wSYtala.dpuf

h t tp s:/ / w ww.inei .gob.pe/m ed i a / MenuRecursivo/publicaci ones_digi ta les/ Est/Líb1254/libro.pdf http:/ /wwl.vipsos.pe/Ipsos_Marketing Expertise 